\title{
SMALL AIR QUALITY SENSORS: IN VIVO TESTING OF ELECTROCHEMICAL CAIRPOL SENSORS IN COMPARISON TO REFERENCE MEASUREMENT
}

\author{
PETRA BAUEROVÁ ${ }^{1}$, ZBYNĚK NOVÁK ${ }^{2}$, ŠTĚPÁN RYCHLÍK ${ }^{3} \&$ JOSEF KEDER $^{1}$ \\ ${ }^{1}$ Czech Hydrometeorological Institute, Tusimice Observatory, Czech Republic \\ ${ }^{2}$ Envitech Bohemia, s.r.o., Czech Republic \\ ${ }^{3}$ Czech Hydrometeorological Institute, Central Air Pollution Laboratory, Czech Republic
}

\begin{abstract}
Use of small air quality sensors is very popular during last few years not only in research but also in public sector. From scientific point of view there are possibilities to cover larger area in air quality monitoring by adding small and easy affordable sensors into the reference measurement networks. Such an application of sensors can be very useful for identifying new hotspots or for development of finescale air quality modelling. Nevertheless, there are some limits for real-time outdoor monitoring that must be considered - higher detection limits and weak possibility to deal with non-standard conditions (low temperatures or high air humidity). Therefore, it is very important to be careful with data postprocessing and data interpretation to not get misleading air quality information. Despite a few independent studies and tests of different types of small sensors have been already done (by universities, companies and also by EU Reference Laboratories), the standardized procedure for testing and verifying the data quality has not yet been developed. Sharing the field-measurement experience with different sensors and the data correction methods is therefore crucial. Here we provide results from test measurement of set of electrochemical Cairclip sensors (Cairpol, FR) for $\mathrm{SO}_{2}, \mathrm{NO}_{2}, \mathrm{O}_{3} / \mathrm{NO}_{2}$ and $\mathrm{CO}$ during summer (in year 2015) and winter period (2017/2018). The best performance both in comparison between pairs and also between sensors and reference monitors (RM) was found out in combined $\mathrm{O}_{3} / \mathrm{NO}_{2}$ Cairclip sensor. Nevertheless, the association of sensor's measured data with sum of $\mathrm{O}_{3}$ and $\mathrm{NO}_{2}$ measured by $\mathrm{RM}$ was much better in summer $(\mathrm{R} 2=0.88)$ than in winter period $(\mathrm{R} 2=0.31)$. Based on the known effect of air temperature and humidity on sensors data quality, we further applied some corrections based on dew point deficit (Td deficit). In this way verified data showed significant improvement in relationship with $\mathrm{RM}$ data $(\mathrm{R} 2=0.88$ with improved slope in summer and $\mathrm{R} 2=0.58$ in winter). Although the quality of sensor's measurement can be influenced by many factors at once and further research is needed to resolve all uncertainties, the simple corrections based on the most critical meteorological factors can be very effective.
\end{abstract}

Keywords: air quality, low-cost sensors, ozone, winter, gases, interference.

\section{INTRODUCTION}

Air quality is long-term one of the most important topic in environmental safety not only for research, governmental or other nongovernmental interested institutions but also for a public sector. With advancing technologies, especially with rapid development of various applications for almost instant sharing of information, is public interest in environmental quality even more deepening. This fact can be observed over the last few years in different citizen-involving projects all around the world [1]-[3]. Increased air pollution in urban and suburban localities enhances the need for a denser and more flexible air quality monitoring network than currently covered by reference monitoring stations in most of the countries. Using small, easy transportable and affordable air quality sensors, so called micro-sensors, is very promising step to meet this need [2], [4]. Such a supplementary monitoring network (in a suitable form) can significantly contribute to the identification of new hotspots [5], to 
better understanding of pollutants transfer or to the development and refinement of air quality models in a complex terrain like cities [6].

The main benefits of small air quality sensors are: small dimensions and weight, easy use, minimal maintenance cost, almost real-time data transfer and, of course, the minimum acquisition costs (generally < \$2500) [3], [7]. At the same time, the resulting risks are: limited (or no) possibility of sensor calibration, higher detection limits, lower sensitivity, weak possibility to deal with wide range of meteorological conditions (air temperature, relative humidity and air pressure) and higher risk of interference with some other pollutants (especially in gaseous electrochemical sensors) [8]-[11].

Several studies and experiments have been already published to show the "behaviour" of different sensor types applied for outdoor monitoring and the associated procedures for checking the accuracy of the measured data based on comparison with reference analysers. Most of these procedures are based on basic statistical processes like the root mean square error (RMSE), correlation (use of correlation coefficients $-r$ and coefficients of determination $-R^{2}$ ), simple linear regression models (LR) or multiple linear regression models (MLR) with explanatory variables like for example air temperature (T), relative humidity (RH), air pressure (p) or sensors uptime [4], [6], [12], [13]. Not always the normality assumptions of the data are fulfilled therefore it is important to consider the use of suitable transformations or the use of non-linear approaches (Spearman correlation coefficient $-r_{S}$, non-linear relationship equations [12]).

In this paper we would like to present the results of comparative field measurement with multiple Cairclip gaseous electrochemical sensors (Cairpol, FR) and air quality Reference Monitors (RM) placed at Tušimice Observatory during summer and winter period. Further we demonstrate the possible data corrections based on air temperature and relative humidity when the sensors are used for continuously outdoor monitoring.

\section{METHODOLOGY}

\subsection{Experimental design and study site}

All measurement took place at Tušimice Observatory of the Czech Hydrometorological Institute (CHMI, in northwest part of the Czech Republic, GPS: $50^{\circ} 22^{\prime} 35.59^{\prime \prime} \mathrm{N}, 13^{\circ}$ $19^{\prime} 39.76$ "E) with distinct industrial background (close to the coal-fired power plants and brown-coal mines). Testing measurement was done during two independent periods during summer months (from June until September 2015; hereinafter referred as summer period) and during winter and early spring months (from the end of November 2017 until the beginning of April 2018; hereinafter referred as winter period). In summer, we have tested only one combined Cairclip sensor for $\mathrm{O}_{3} / \mathrm{NO}_{2}$. During winter, we have tested a set of Cairclip sensors in pairs (hereinafter referred as sensor-type_1 and sensor-type_2) for $\mathrm{SO}_{2}, \mathrm{NO}_{2}, \mathrm{O}_{3} / \mathrm{NO}_{2}$ and $\mathrm{CO}$ (for individual technical specifications see Section 2.3). All sensors were kept in housing (airflow box) right next to the air quality RM (Fig. 1). The measuring interval was 10 min for each pollutant.

\subsection{Technical specification of reference measurement}

For quality control of sensors performance classical comparison with data measured by reference analysers from CHMI air quality monitoring network was used. The $\mathrm{SO}_{2}$ analyser T100 (Teledyne API, California, US) is based on UV fluorescence principle, its minimum range is between $0-50 \mathrm{ppb}$, maximum range between $0-20 \mathrm{ppm}$, lower detectable limit is 

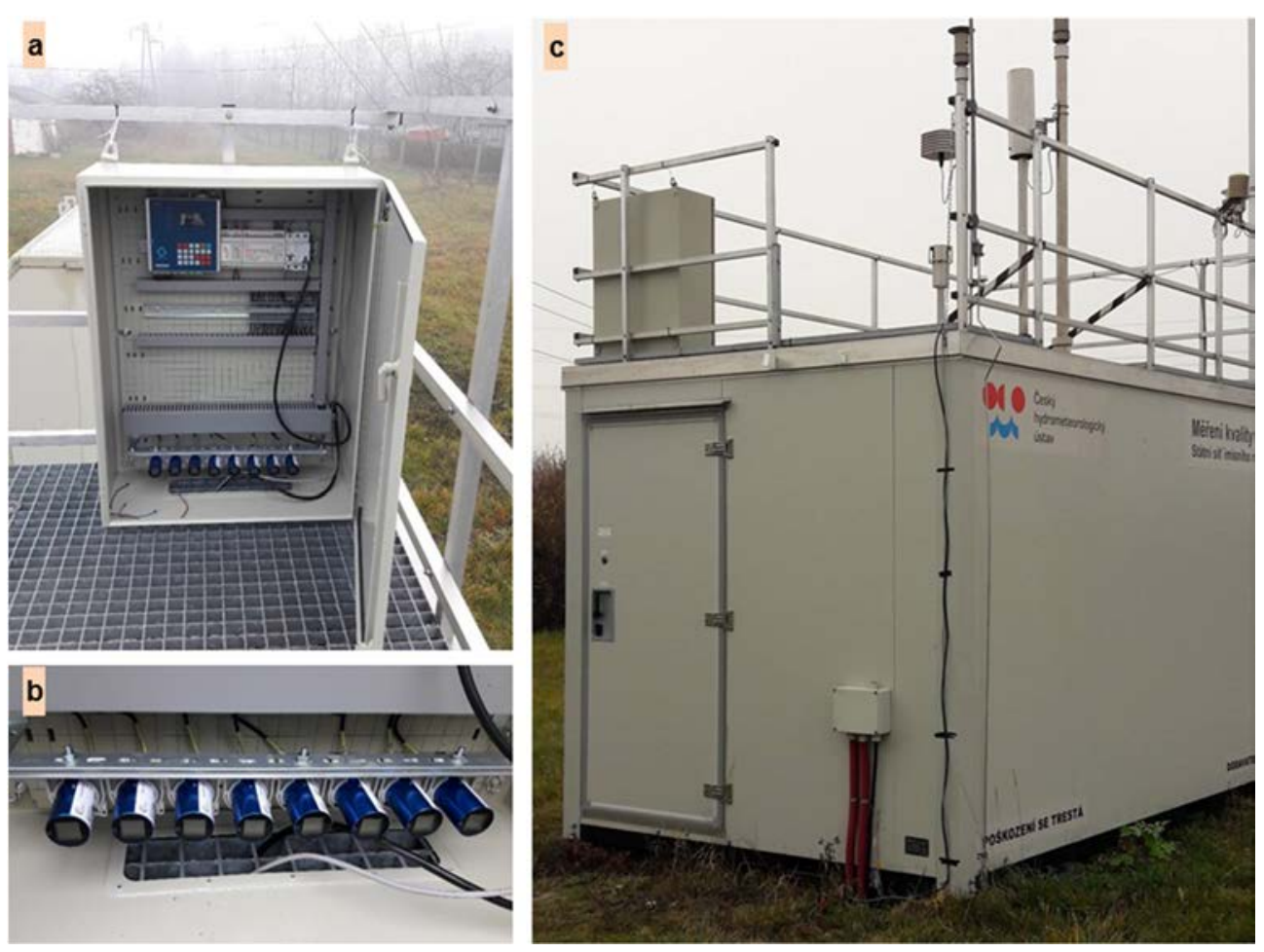

Figure 1: Sensors testing during winter period. Pairs of Cairclip sensors for $\mathrm{SO}_{2}, \mathrm{NO}_{2}$, $\mathrm{O}_{3} / \mathrm{NO}_{2}$ and $\mathrm{CO}$ (b) placed in airflow box (a) in the immediate vicinity of reference monitoring (c). (Source: Photo: P. Bauerová.)

0.4 ppb. The $\mathrm{NO}_{2}$ analyser T200 (Teledyne API, California, US) is based on chemoluminiscence detection principle, minimum/maximum range and lower detectable limit is the same as in $\mathrm{SO}_{2}$ analyser. The T400 (Teledyne API, California, US) for $\mathrm{O}_{3}$ is UV absorption analyser with minimum range between $0-100 \mathrm{ppb}$, maximum range $0-10 \mathrm{ppm}$, and detection limit $<0.4 \mathrm{ppb}$ [14].

All the above-mentioned analysers are regularly controlled and calibrated according to the national legislation and applicable international standards (ISO/IEC 17025:2005, General requirements for the competence of testing and calibration laboratories).

\subsection{Technical specification of sensors}

The Cairclip electrochemical sensors for gaseous pollutants (Cairpol, FR) are small tubeshaped measuring units with diameter of $32 \mathrm{~mm}$, length $62 \mathrm{~mm}$ and weight $55 \mathrm{~g}$ (see Fig. 1(b)). Each sensor has own battery with operating time from 24 to 36 hours (when fully charged) or can be connected directly to the power supply with demands 5VDC /500 mA.

The $\mathrm{SO}_{2}$ Cairclip sensor has measuring range between $0-1,000 \mathrm{ppb}$, detection limit of $50 \mathrm{ppb}$ and reported uncertainty $<25 \%$. According to the technical datasheet there could be a strong negative interference with $\mathrm{NO}_{2}$ and $\mathrm{O}_{3}$ oxides $(\sim-125 \%)$ or positive interference with $\mathrm{H}_{2} \mathrm{~S}(\sim 5 \%)$. 
The $\mathrm{NO}_{2}$ Cairclip sensor has measuring range between 0-250 ppb, detection limit of $20 \mathrm{ppb}$ and reported uncertainty $<30 \%$. Beside negative interference with sulphur compounds, there is mentioned strong interference with $\mathrm{Cl}_{2}$ and $\mathrm{O}_{3}(\sim 80 \%)$.

The combined $\mathrm{O}_{3} / \mathrm{NO}_{2}$ Cairclip sensor has the same measuring range, limit of detection and uncertainty as the $\mathrm{NO}_{2}$ sensor itself. Given the algorithm for the transformation of the sensor's responses into $\mathrm{O} 3$ concentration is not known [15], we assumed this combined sensor is measuring approximate sum of $\mathrm{O}_{3}$ and $\mathrm{NO}_{2}$ (based on the known interference of these two oxides [4], [16]).

The CO Cairclip sensor has measuring range between $0-20 \mathrm{ppm}$, limit of detection at $0.05 \mathrm{ppm}$ and uncertainty $<25 \%$. Possible interferences are mentioned with $\mathrm{H}_{2}, \mathrm{H}_{2} \mathrm{~S}, \mathrm{NO}_{\mathrm{x}}$, $\mathrm{SO}_{2}$ or acid gases.

All the above mentioned technical specifications of these sensors are based on the laboratory testing in standard operating conditions at the $\mathrm{T}=20^{\circ} \mathrm{C}\left( \pm 2{ }^{\circ} \mathrm{C}\right), \mathrm{RH}=50 \%( \pm$ $10 \%)$ and $\mathrm{p}=1013 \mathrm{hPa}( \pm 5 \%)$. Operating conditions mentioned by manufacturer are $\mathrm{T}$ from $-20^{\circ} \mathrm{C}$ to $50^{\circ} \mathrm{C}$ and $\mathrm{RH}$ from $15 \%$ to $90 \%$ (non-condensing conditions).

\subsection{Data analysis and quality control}

All measured data from Cairclip sensors were cleaned before processing. Any outages in measuring were treated as missing values. Hourly averages were calculated from all 10 minutes data (measured in ppb, with except for $\mathrm{CO}$ in $\mathrm{ppm}$ ). Extreme peaks in hourly concentrations were set as three times the maximum hourly concentration measured by RM (similarly as in [17]) and were removed from the dataset (detected only in $\mathrm{SO}_{2}$ sensors during winter period).

Because the sensors measured data were not normally distributed and any of the possible transformations to the Gaussian distribution (logarithmic, square root or Boxcox transformation) showed as non-effective (Shapiro-Wilk normality test with $\mathrm{p}<10^{-16}$ ) as well as the effort to adapt the data to another type of distribution (for example gamma distribution; data were bimodal distributed in both summer and winter period), we performed simple correlations based on the non-parametric Spearman correlation coefficients ( $\mathrm{r}_{\mathrm{S}}$; similarly as in [12]) and we calculated the coefficient of determination $\left(\mathrm{R}^{2}\right)$ according to a "line of best fit" equation.

First step of data quality control was the comparison in-between the pairs of sensor types. Second step was the comparison of measured sensor data and RM data. As a third step of analysis, we have calculated a sensor's performance ratio (SPR) according to the eqn (1) and we further compared it with dew point deficit (deficit $T_{d}$ ) because of the known effect of temperature and relative humidity on the electrochemical sensor's performance. The deficit $\mathrm{T}_{\mathrm{d}}$ was calculated according to the eqns (2)-(4)

$$
\begin{gathered}
S P R=\text { Cairclip }_{\text {measured }} / \mathrm{RM}, \\
T d=\frac{240.97}{[(17.502 / A)-1]},
\end{gathered}
$$

while parameter $A$ was calculated as: 


$$
A=[\ln (R H / 100))]+\left[\frac{(17.502 \cdot T)}{(240.97+T)}\right],
$$

where $R H$ is relative humidity $(\%)$ and $T$ is air temperature $\left({ }^{\circ} \mathrm{C}\right)$.

$$
\text { deficit } T_{d}=T-T_{d}
$$

Finally, we calculated a correction performance index (CPI) based on the equation of the relationship between sensor's performance and $T_{d}$ deficit (by substituting the $T_{d}$ deficit as $x$ variable into the quadratic eqn (5)) and divided the original sensor's measured data by this

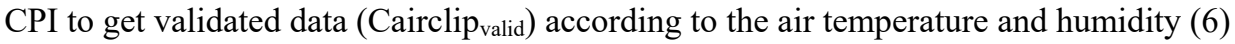

$$
\begin{gathered}
C P I=\mathrm{a} *\left(\text { deficit } T_{d}\right)^{2}+\mathrm{b} * \text { deficit } T_{d}+\mathrm{c}, \\
\text { Cairclip }_{\text {valid }}=\text { Cairclip }_{\text {measured }} / C P I .
\end{gathered}
$$

\section{RESULTS}

\subsection{Summer period: testing of $\mathrm{O}_{3} / \mathrm{NO}_{2}$ Cairclip sensor}

The measured concentrations of $\mathrm{O}_{3}$ and $\mathrm{NO}_{2}$ by Cairclip sensor and RMs are listed in Table 1. The average values of air temperature, relative humidity and calculated $T_{d}$ deficit during the summer months are listed in Table 2.

There was a strong positive correlation between the hourly concentrations measured by Cairclip sensor and by RM $\left(\mathrm{r}_{\mathrm{S}}=0.93, \mathrm{p}<0.001\right.$, with linear interpolation $\mathrm{R}^{2}=0.88$, slope $=$ 0.97 ; Fig. 2). The SPR ranged between $\min =0.30$ and $\max =1.99$ value (mean $=0.79, \mathrm{SD}$ $=0.12$ ). Furthermore, there was found significant correlation between the SPR and $T_{d}$ deficit $\left(r_{S}=0.76, p<0.001\right.$, with quadratic interpolation $\mathrm{R}^{2}=0.59 ;$ Fig. 3$)$. The CPI was calculated from the quadratic interpolation equation $\left(\mathrm{CPI}=-0.0009 *\left(\mathrm{~T}_{\mathrm{d}} \text { deficit }\right)^{2}+0.0303 * \mathrm{~T}_{\mathrm{d}}\right.$ deficit + 0.6431 ) and was used for validation of sensor's measured data (Cairclip valid $_{\text {vaiclip }}=$ Casured $_{\text {mas }}$ / CPI) according to the effect of $\mathrm{T}_{\mathrm{d}}$ deficit $\left(\right.$ Cairpol $_{\text {valid: }} \mathrm{R}^{2}=0.88$, slope $=1.01$; Fig. 2$)$. The hourly averages of validated $\mathrm{O}_{3} / \mathrm{NO}_{2}$ Cairclip sensor's data ranged between $\min =10.54 \mathrm{ppb}$ and $\max =91.93 \mathrm{ppb}($ mean $=41.86, \mathrm{SD}=15.44)$.

Table 1: Descriptive statistics of $\mathrm{O}_{3}$ and $\mathrm{NO}_{2}$ hourly concentrations measured by

\begin{tabular}{|c|c|c|c|c|c|c|c|}
\hline Measurement & Analyzer & $\mathbf{N}$ & Mean & Min & Max & SD & SE \\
\hline $\mathrm{O}_{3} / \mathrm{NO}_{2} \mathbf{1}_{1}(\mathrm{ppb})$ & Cairclip & 1235 & 34.24 & 6.92 & 81.55 & 14.80 & 0.42 \\
\hline $\mathrm{O}_{3} \_\mathrm{RM}(\mathrm{ppb})$ & $\mathrm{T} 400$ & 1235 & 38.53 & 4.21 & 84.91 & 14.88 & 0.42 \\
\hline $\mathrm{NO}_{2}$ RM (ppb) & $\mathrm{T} 200$ & 1235 & 3.80 & 0.27 & 22.69 & 2.74 & 0.08 \\
\hline $\mathrm{O}_{3}+\mathrm{NO}_{2} \mathrm{RM}_{(\mathrm{ppb})}$ & & 1235 & 42.33 & 11.21 & 88.28 & 14.39 & 0.41 \\
\hline
\end{tabular}
combined $\mathrm{O}_{3} / \mathrm{NO}_{2}$ Cairclip sensor and by Reference Monitors (RM) during the summer period. $\mathrm{N}=$ number of valid observations, $\mathrm{SD}=$ standard deviation and $\mathrm{SE}=$ standard error of mean. 
Table 2: $\quad$ The measured hourly averages of air temperature $(\mathrm{T})$, relative humidity $(\mathrm{RH})$ and calculated dew point deficit $\left(\mathrm{T}_{\mathrm{d}}\right.$ deficit) during the summer months of sensors testing measurement. $\mathrm{N}=$ number of valid observations, $\mathrm{SD}=$ standard deviation.

\begin{tabular}{|l|c|cc|cc|cc|}
\hline \multirow{2}{*}{ Month } & \multirow{2}{*}{$\mathbf{N}$} & \multicolumn{2}{|c|}{$\left.\mathbf{T}^{\circ}{ }^{\circ} \mathbf{C}\right)$} & \multicolumn{2}{c|}{$\mathbf{R H ~ ( \% )}$} & \multicolumn{2}{c|}{$\mathbf{T}_{\mathbf{d}}$ deficit $\left({ }^{\circ} \mathbf{C}\right)$} \\
& & mean $\pm \mathbf{S D}$ & $\mathbf{m i n} / \mathbf{m a x}$ & $\mathbf{m e a n} \pm \mathbf{S D}$ & $\mathbf{m i n} / \mathbf{m a x}$ & $\mathbf{m e a n} \pm \mathbf{S D}$ & $\mathbf{m i n} / \mathbf{m a x}$ \\
\hline \multirow{2}{*}{ June } & \multirow{2}{*}{460} & $15.35 \pm 4.12$ & $6.88 / 27.18$ & $\begin{array}{c}72.09 \pm \\
16.02\end{array}$ & $\begin{array}{c}35.67 / \\
100.00\end{array}$ & $5.65 \pm 3.73$ & $0.00 / 15.47$ \\
\hline \multirow{2}{*}{ July } & \multirow{2}{*}{662} & $20.02 \pm 5.19$ & $7.57 / 34.00$ & $\begin{array}{c}58.91 \pm \\
18.26\end{array}$ & $\begin{array}{c}24.33 / \\
97.67\end{array}$ & $8.58 \pm 5.02$ & $0.37 / 22.04$ \\
\hline \multirow{2}{*}{ August } & \multirow{2}{*}{113} & $21.53 \pm 5.83$ & $9.20 / 32.60$ & $\begin{array}{c}50.00 \pm \\
19.80\end{array}$ & $\begin{array}{c}25.00 / \\
94.00\end{array}$ & $\begin{array}{c}10.84 \pm \\
6.04\end{array}$ & $0.94 / 22.55$ \\
\hline
\end{tabular}

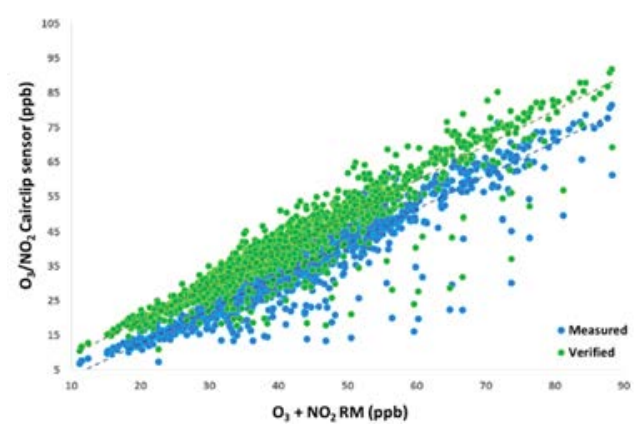

Figure 2: The relationship between $\mathrm{O}_{3}$ and $\mathrm{NO}_{2}$ concentrations measured by combined $\mathrm{O}_{3} / \mathrm{NO}_{2}$ Cairpol sensor (y axis) and by Reference Monitor (x axis) during the summer period. The blue circles are the original sensor measured data $\left(\mathrm{R}^{2}=0.88\right.$, slope $=0.96)$. The green circles are the validated sensor data according to the $T_{d}$ deficit effect on sensor's performance $\left(\mathrm{R}^{2}=0.88\right.$, slope $\left.=1.01\right)$.

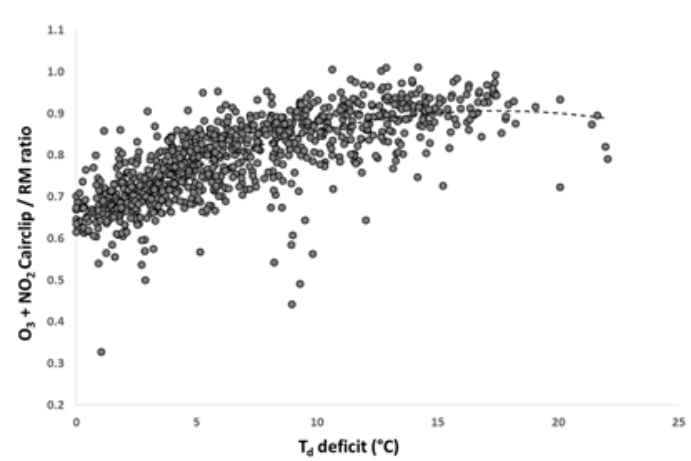

Figure 3: The relationship between sensor's performance (SPR; y axis) and dew point deficit (x axis) during the summer testing period. The effect of $T_{d}$ deficit on sensor's performance was fitted with polynomial equation $\left(\mathrm{y}=-0.0009 * \mathrm{x}^{2}+\right.$ $\left.0.0303 * x+0.6431 ; R^{2}=0.59\right)$. 


\subsection{Winter period: testing of $\mathrm{SO}_{2}, \mathrm{NO}_{2}, \mathrm{O}_{3} / \mathrm{NO}_{2}$ and $\mathrm{CO}$ Cairclip sensors}

The concentrations of $\mathrm{SO}_{2}, \mathrm{NO}_{2}, \mathrm{O}_{3} / \mathrm{NO}_{2}$ and $\mathrm{CO}$ measured by Cairclip sensors and by $\mathrm{RM}$ during winter testing period are listed in Table 3 (except the CO where is no available RM). The average values of air temperature, relative humidity and $T_{d}$ deficit during each month of winter testing period are listed in Table 4.

There was detected a significant discrepancy in measured concentrations within the pairs of $\mathrm{SO}_{2}$ and $\mathrm{CO}$ Cairclip sensors (Table 3), therefore these sensors were not further statistically analysed. The $\mathrm{NO}_{2}$ and $\mathrm{O}_{3} / \mathrm{NO}_{2}$ Cairclip sensors showed strong positive correlation within each other in pairs $\left(\mathrm{r}_{\mathrm{S}}=0.99, \mathrm{p}<0.001\right.$ for both, see Table 3$)$. In all Cairclip sensors was identified noticeable data drift in sense of increased measured concentrations after the 8th February 2018 (for $\mathrm{NO}_{2}$ and $\mathrm{O}_{3} / \mathrm{NO}_{2}$ Cairlip sensors see increase in max hourly average values in Table 5 and Fig. 4).

The $\mathrm{NO}_{2}$ Cairclip sensors showed non-significant correlation with $\mathrm{NO}_{2} \mathrm{RM}\left(\mathrm{r}_{\mathrm{S}}=0.03, \mathrm{p}\right.$ $=0.09 ; \mathrm{R}^{2}=0.003$ with quadratic interpolation). Generally, the $\mathrm{NO}_{2}$ concentrations measured by Cairclip sensor were much higher than the concentrations measured by RM (Table 3, Table 5), therefore the SPR values here were also very high $(\min =0.74, \max =52.73$, mean $=4.53, \mathrm{SD}=3.77$ ).

Combined $\mathrm{O}_{3} / \mathrm{NO}_{2}$ sensors showed significant positive correlation with both $\mathrm{O}_{3}$ itself and sum of $\mathrm{O}_{3}$ and $\mathrm{NO}_{2}$ measured by $\mathrm{RM}\left(\mathrm{r}_{\mathrm{S}}=0.22, \mathrm{p}<0.001, \mathrm{R}^{2}=0.24\right.$ with quadratic interpolation; $\mathrm{r}_{\mathrm{S}}=0.30, \mathrm{p}<0.001, \mathrm{R}^{2}=0.31$ with quadratic interpolation; respectively). The $\mathrm{SPR}$ values were between $\min =0.25$ and $\max =1.48($ mean $=0.52, \mathrm{SD}=0.17)$. The significant negative correlation was found in this case between SPR $\left(\mathrm{O}_{3} / \mathrm{NO}_{2}\right.$ Cairclip sensor / sum of $\mathrm{O}_{3}$ and $\left.\mathrm{NO}_{2} \mathrm{RM}\right)$ and $\mathrm{T}_{\mathrm{d}}$ deficit $\left(\mathrm{r}_{\mathrm{s}}=-0.55, \mathrm{p}<0.001, \mathrm{R}^{2}=0.34\right.$ with quadratic function; Fig. 5). The CPI was calculated from the interpolation equation (CPI $=0.0047 *\left(\mathrm{~T}_{\mathrm{d}}\right.$ deficit $)^{2}-0.0802 * T_{d}$ deficit +0.7002$)$ and sensor's data were validated according to the effect of $\mathrm{T}_{\mathrm{d}}$ deficit (Cairpol $\mathrm{l}_{\text {valid: }} \mathrm{R}^{2}=0.58$; Fig. 6 ). The hourly averages of validated $\mathrm{O}_{3} / \mathrm{NO}_{2}$ Cairclip sensor's data ranged between $\min =17.79 \mathrm{ppb}$ and $\max =85.54 \mathrm{ppb}($ mean $=30.71$, $\mathrm{SD}=10.41)$

Table 3: Descriptive statistics of $\mathrm{SO}_{2}, \mathrm{NO}_{2}, \mathrm{O}_{3} / \mathrm{NO}_{2}$ and $\mathrm{CO}$ concentrations measured by Cairclip sensors and their analogous RM (missing in case of $\mathrm{CO}$ ) during winter period. $\mathrm{N}=$ number of valid observations, $\mathrm{SD}=$ standard deviation and $\mathrm{SE}=$ standard error of mean. Sensors highlighted in brown had significant correlation within pairs $\left(\mathrm{r}_{\mathrm{S}}=0.99, \mathrm{p}<0.001\right)$. Sensors highlighted in red had significant discrepancy in measured concentrations within pairs.

\begin{tabular}{|c|c|c|c|c|c|c|c|}
\hline Measurement & Analyzer & $\mathbf{N}$ & Mean & Min & Max & SD & SE \\
\hline $\mathrm{SO}_{2} \_1$ (ppb) & Cairclip & 3042 & 67.28 & 45.77 & 145.53 & 13.60 & 0.25 \\
\hline $\mathrm{SO}_{2} \_2$ (ppb) & Cairclip & 3042 & 3.43 & 0.00 & 57.85 & 6.55 & 0.12 \\
\hline $\mathrm{SO}_{2} \mathrm{RM}$ (ppb) & $\mathrm{T} 100$ & 3042 & 1.95 & 0.50 & 15.46 & 1.73 & 0.03 \\
\hline $\mathrm{NO}_{2} \_1$ (ppb) & Cairclip & 3041 & 23.19 & 17.35 & 42.27 & 3.39 & 0.06 \\
\hline $\mathrm{NO}_{2} \_2$ (ppb) & Cairclip & 3041 & 22.15 & 16.53 & 41.38 & 3.52 & 0.06 \\
\hline $\mathrm{NO}_{2} \mathrm{RM}(\mathrm{ppb})$ & $\mathrm{T} 200$ & 3041 & 7.67 & 0.52 & 29.12 & 4.51 & 0.08 \\
\hline $\mathrm{O}_{3} / \mathrm{NO}_{2}{ }_{1} 1$ (ppb) & Cairclip & 3054 & 15.18 & 9.90 & 34.13 & 3.32 & 0.06 \\
\hline $\mathrm{O}_{3} / \mathrm{NO}_{2} 2(\mathrm{ppb})$ & Cairclip & 3054 & 16.14 & 10.90 & 35.23 & 3.28 & 0.06 \\
\hline $\mathrm{O}_{3} \mathrm{RM}$ (ppb) & $\mathrm{T} 400$ & 3054 & 23.42 & 0.50 & 54.19 & 11.14 & 0.20 \\
\hline CO_1 (ppm) & Cairclip & 3187 & 1.21 & 0.81 & 2.78 & 0.28 & 0.01 \\
\hline CO_2 (ppm) & Cairclip & 3187 & 5.91 & 0.94 & 15.83 & 5.82 & 0.10 \\
\hline
\end{tabular}



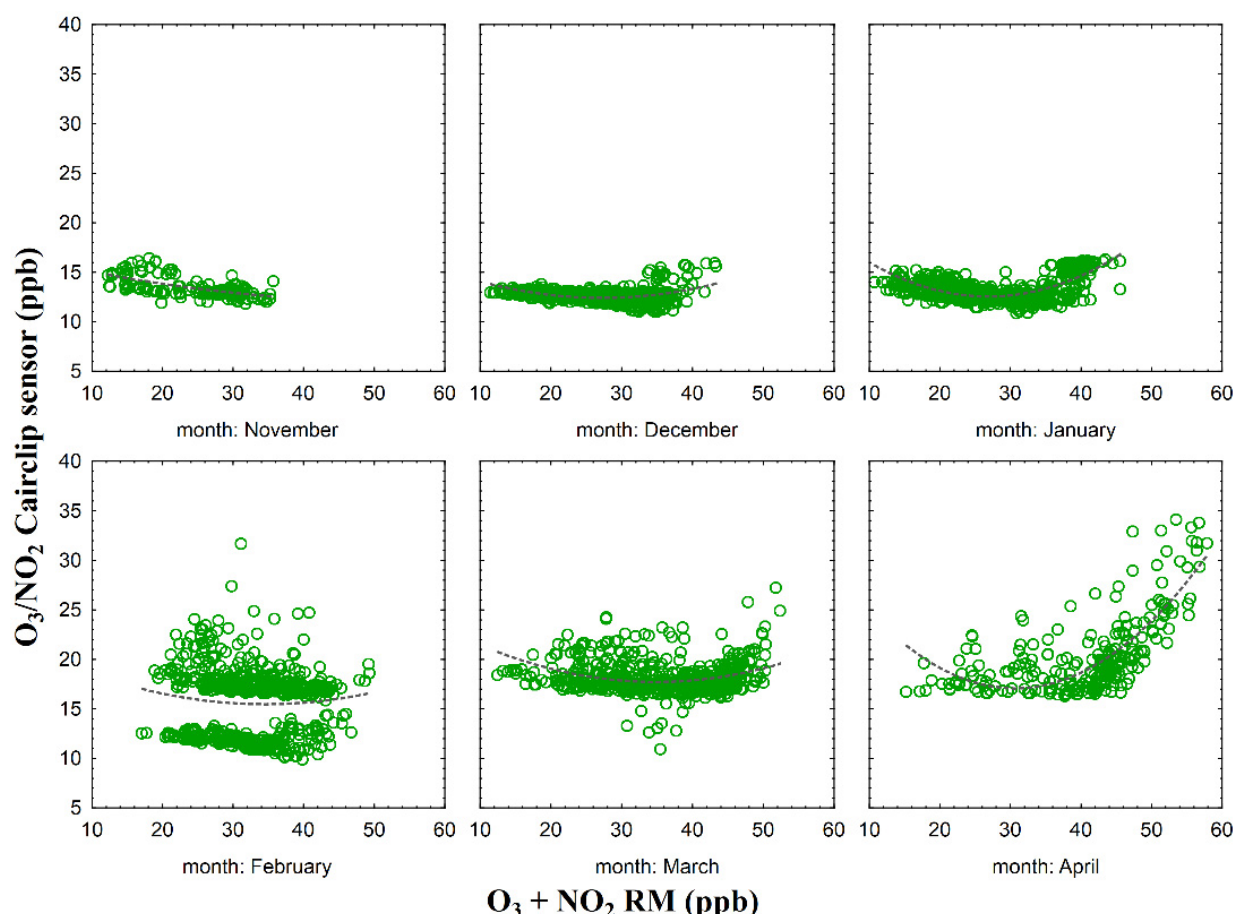

Figure 4: The relationship between $\mathrm{O}_{3}$ and $\mathrm{NO}_{2}$ concentrations measured by combined $\mathrm{O}_{3} / \mathrm{NO}_{2}$ Cairpol sensor (y axis) and by Reference Monitors (x axis) during each month of winter period.

Table 4: The measured hourly averages of air temperature (T), relative humidity (RH) and dew point deficit (Td deficit) during each month of winter testing period. $\mathrm{N}=$ number of valid observations, $\mathrm{SD}=$ standard deviation.

\begin{tabular}{|l|c|cc|cc|cc|}
\hline \multirow{2}{*}{ Month } & \multirow{2}{*}{$\mathbf{N}$} & \multicolumn{2}{|c|}{$\mathbf{T}\left({ }^{\circ} \mathbf{C}\right)$} & \multicolumn{2}{|c|}{$\mathbf{R H}(\%)$} & \multicolumn{2}{c|}{$\mathbf{T}_{\mathbf{d}} \mathbf{d e f i c i t}\left({ }^{\circ} \mathbf{C}\right)$} \\
& & $\mathbf{m e a n} \pm \mathbf{S D}$ & $\begin{array}{c}\mathbf{m i n} / \\
\mathbf{m a x}\end{array}$ & $\mathbf{m e a n} \pm \mathbf{S D}$ & $\begin{array}{c}\mathbf{m i n} / \\
\mathbf{m a x}\end{array}$ & $\mathbf{m e a n} \pm \mathbf{S D}$ & $\begin{array}{c}\mathbf{m i n} / \\
\mathbf{m a x}\end{array}$ \\
\hline November & 143 & $2.95 \pm 1.40$ & $\begin{array}{c}-1.15 / \\
5.85\end{array}$ & $85.95 \pm 10.39$ & $\begin{array}{c}63.0 / \\
100.0\end{array}$ & $2.21 \pm 1.73$ & $\begin{array}{c}0.00 / \\
6.40\end{array}$ \\
\hline December & 673 & $1.90 \pm 3.17$ & $\begin{array}{c}-4.25 / \\
11.75\end{array}$ & $83.56 \pm 9.84$ & $\begin{array}{c}54.0 / \\
100.0\end{array}$ & $2.59 \pm 1.67$ & $\begin{array}{c}0.00 / \\
8.50\end{array}$ \\
\hline January & 652 & $3.06 \pm 3.07$ & $\begin{array}{c}-6.85 / \\
9.45\end{array}$ & $86.61 \pm 8.88$ & $\begin{array}{c}51.0 / \\
100.0\end{array}$ & $2.10 \pm 1.54$ & $\begin{array}{c}0.00 / \\
9.41\end{array}$ \\
\hline February & 602 & $-2.20 \pm 4.27$ & $\begin{array}{c}-14.45 / \\
7.15\end{array}$ & $74.57 \pm 13.45$ & $\begin{array}{c}30.0 / \\
99.0\end{array}$ & $4.11 \pm 2.59$ & $\begin{array}{c}0.14 / \\
15.00\end{array}$ \\
\hline March & 577 & $2.86 \pm 4.39$ & $\begin{array}{c}-9.05 / \\
12.25\end{array}$ & $76.76 \pm 14.09$ & $\begin{array}{c}35.0 / \\
100.0\end{array}$ & $3.91 \pm 2.73$ & $\begin{array}{c}0.00 / \\
13.97\end{array}$ \\
\hline April & 96 & $9.39 \pm 5.19$ & $\begin{array}{c}2.85 / \\
20.95\end{array}$ & $63.41 \pm 14.80$ & $\begin{array}{c}34.0 / \\
90.0\end{array}$ & $7.08 \pm 3.89$ & $\begin{array}{c}1.52 / \\
16.36\end{array}$ \\
\hline
\end{tabular}


Table 5: Concentrations of $\mathrm{NO}_{2}$ and $\mathrm{O}_{3}$ measured by $\mathrm{NO}_{2}$ and combined $\mathrm{O}_{3} / \mathrm{NO}_{2}$ Cairclip sensor (white columns) and by Reference Monitors (brown columns) in each month of winter testing period. SD = standard deviation. Min values are in blue, max values are in red.

\begin{tabular}{|c|c|c|c|c|c|c|c|c|c|}
\hline \multirow{2}{*}{ Month } & \multirow[b]{2}{*}{$\mathbf{N}$} & \multicolumn{2}{|c|}{$\begin{array}{c}\mathrm{NO}_{2}{ }_{\text {(ppb) }}^{1} \text { Cairclip } \\
\text { (ppb) }\end{array}$} & \multicolumn{2}{|c|}{$\begin{array}{c}\mathrm{O}_{3} / \mathrm{NO}_{2} \text { Cairclip } \\
\text { (ppb) }\end{array}$} & \multicolumn{2}{|c|}{$\mathrm{NO}_{2} \mathrm{RM}$ (ppb) } & \multicolumn{2}{|c|}{$\mathrm{O}_{3} \mathrm{RM}$ (ppb) } \\
\hline & & $\begin{array}{c}\operatorname{mean} \pm \\
\text { SD }\end{array}$ & $\begin{array}{c}\min / \\
\max \end{array}$ & 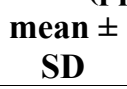 & $\begin{array}{l}\min / \\
\max \end{array}$ & $\begin{array}{c}\text { mean } \pm \\
\text { SD }\end{array}$ & $\begin{array}{c}\min / \\
\max \end{array}$ & $\begin{array}{c}\operatorname{mean} \\
\text { SD }\end{array}$ & \\
\hline $\mathbf{r}$ & 143 & $\begin{array}{c}21.75 \pm \\
1.08\end{array}$ & $\begin{array}{c}20.12 / \\
24.98\end{array}$ & $\begin{array}{c}13.44 \pm \\
0.99\end{array}$ & $\begin{array}{c}11.83 / \\
16.43\end{array}$ & & & & \\
\hline D & 673 & $\begin{array}{c}20.83 \pm \\
0.70 \\
\end{array}$ & $\begin{array}{c}19.05 / \\
24.43 \\
\end{array}$ & \begin{tabular}{|c|}
$12.64 \pm$ \\
0.64 \\
\end{tabular} & & & & $\begin{array}{r}19 . \\
9 . \\
\end{array}$ & \\
\hline January & 652 & $\begin{array}{c}21.23 \pm \\
1.36\end{array}$ & $\begin{array}{l}18.40 / \\
24.85\end{array}$ & $\begin{array}{c}13.24 \pm \\
1.15\end{array}$ & $\begin{array}{c}10.90 / \\
16.30 \\
\end{array}$ & $\begin{array}{c}7.4 \\
4 .\end{array}$ & & $\begin{array}{r}20 . \\
10 \\
\end{array}$ & $\begin{array}{l}1.20 / \\
43.81\end{array}$ \\
\hline Febrt & 602 & $\begin{array}{c}23.37 \pm \\
3.61 \\
\end{array}$ & $\begin{array}{c}17.35 / \\
40.30 \\
\end{array}$ & \begin{tabular}{|c|}
$15.69 \pm$ \\
3.41 \\
\end{tabular} & $\begin{array}{l}9.90 / \\
31.68 \\
\end{array}$ & $\begin{array}{l}8.94 \pm \\
4.29 \\
\end{array}$ & & \begin{tabular}{|c|}
$23.70 \pm$ \\
8.57 \\
\end{tabular} & $\begin{array}{l}1.60 / \\
42.31 \\
\end{array}$ \\
\hline & 577 & $\begin{array}{c}26.18 \pm \\
1.75 \\
\end{array}$ & $\begin{array}{c}18.75 / \\
35.83 \\
\end{array}$ & \begin{tabular}{|c|}
$18.14 \pm$ \\
1.63 \\
\end{tabular} & \begin{tabular}{|l|}
$10.97 /$ \\
27.27 \\
\end{tabular} & $\begin{array}{c}7.78 \pm \\
3.63 \\
\end{array}$ & $\begin{array}{l}\mathbf{0 . 5 2 /} \\
20.07 \\
\end{array}$ & \begin{tabular}{|c|}
$28.11 \pm$ \\
10.37 \\
\end{tabular} & $\begin{array}{l}1.70 / \\
49.52 \\
\end{array}$ \\
\hline April & 96 & \begin{tabular}{|c|}
$28.49 \pm$ \\
3.99 \\
\end{tabular} & $\begin{array}{c}24.37 / \\
\mathbf{4 2 . 2 7}\end{array}$ & $\begin{array}{c}20.28 \pm \\
3.91\end{array}$ & \begin{tabular}{|l|}
$16.30 /$ \\
$\mathbf{3 4 . 1 3}$ \\
\end{tabular} & $\begin{array}{c}5.54 \pm \\
4.10 \\
\end{array}$ & $\begin{array}{l}0.52 / \\
19.92 \\
\end{array}$ & \begin{tabular}{|c|}
$34.55 \pm$ \\
12.05 \\
\end{tabular} & $\begin{array}{l}2.71 / \\
\mathbf{5 4 . 1 9}\end{array}$ \\
\hline
\end{tabular}

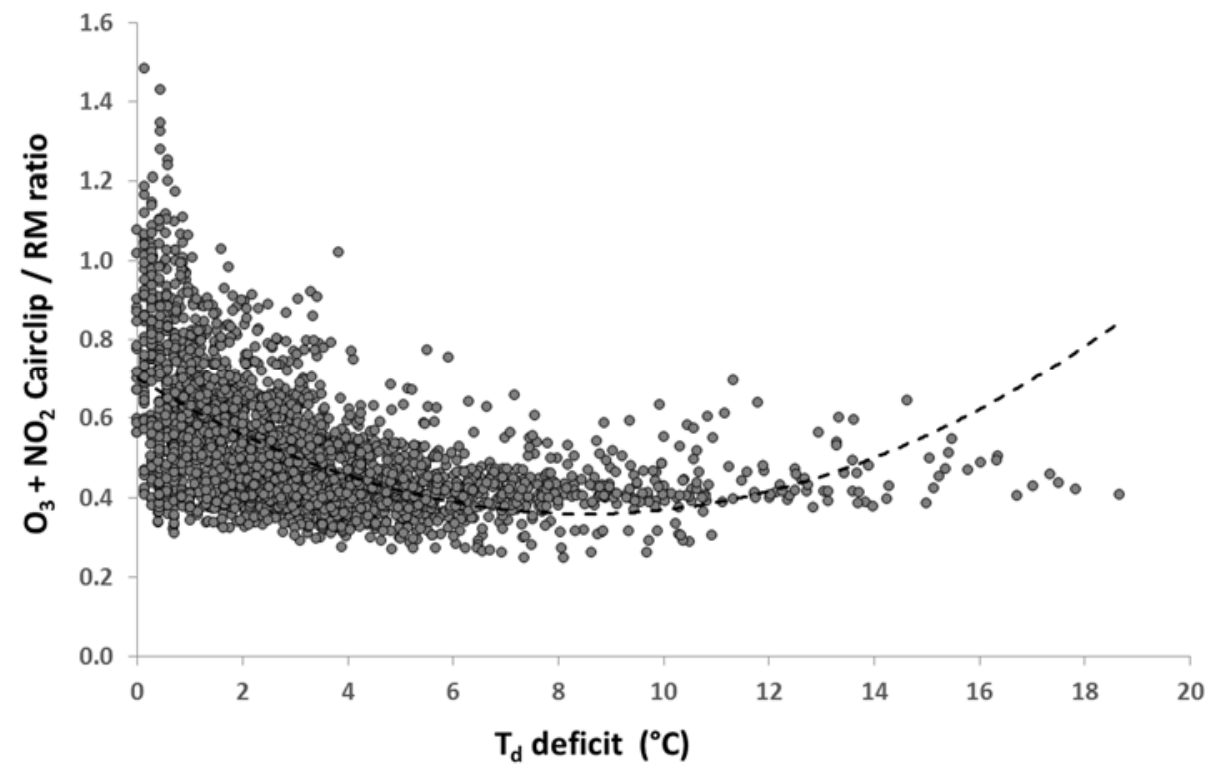

Figure 5: Relationship between $\mathrm{O}_{3} / \mathrm{NO}_{2}$ sensor's performance ( $\mathrm{SPR}=$ Cairclip / $\mathrm{RM}$ ratio on $\mathrm{y}$ axis) and dew point deficit ( $\mathrm{T}_{\mathrm{d}}$ deficit on $\mathrm{x}$ axis) during the winter testing period. The effect of $T_{d}$ deficit on sensors performance was fitted with polynomial equation $\left(\mathrm{y}=0.0047 *\left(\mathrm{~T}_{\mathrm{d}} \text { deficit }\right)^{2}-0.0802 * \mathrm{~T}_{\mathrm{d}}\right.$ deficit $+0.7002 ; \mathrm{R}^{2}$ $=034)$. 


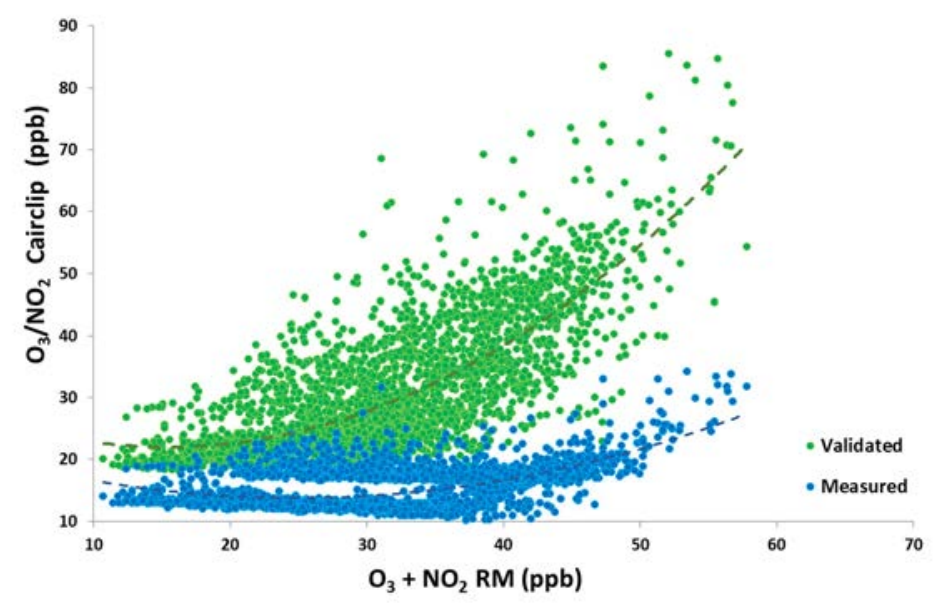

Figure 6: The relationship between $\mathrm{O}_{3}$ and $\mathrm{NO}_{2}$ concentrations measured by combined $\mathrm{O}_{3} / \mathrm{NO}_{2}$ Cairpol sensor (on y axis) and by Reference Monitors (RM on x axis) during the winter period. The blue circles are the original sensor measured data $\left(R^{2}=0.34\right)$. The green circles are the validated sensor data according to the $T_{d}$ deficit effect on sensor's performance $\left(\mathrm{R}^{2}=0.58\right)$.

\section{DISCUSSION}

Although small sensors may serve as a useful additional tools in air quality monitoring network, it is always important to have on mind that their performance can be very different during the continuous long-term outdoor monitoring than during the initial laboratory testing [9], [10], [18].

In this study we performed a testing field measurement of various Cairpol electrochemical gaseous sensors $\left(\mathrm{SO}_{2}, \mathrm{CO}, \mathrm{NO}_{2}\right.$ and $\left.\mathrm{O}_{3} / \mathrm{NO}_{2}\right)$ during different seasons. The results show that there is a high variability in data quality not only in between different types of Cairclip sensors but also within one type of sensor during the measuring time. While in summer months the performance of combined $\mathrm{O}_{3} / \mathrm{NO}_{2}$ sensor was quite satisfactory (Fig. 2), in winter and early spring months the performance of all Cairclip sensors was generally weak (Fig. 6). In winter testing period there was also an evident increase in all Cairclip sensors measured data during February 2018. The reason of such a data drift was not detected, but probably it may be related to the higher pollutant concentrations during February inversions or to the rapid changes in air temperature and relative humidity (very low temperatures and low humidity). Anyway, after the middle of February and with coming early spring months the performance of sensors was improving.

In case of $\mathrm{NO}_{2}$ Cairclip sensor we came to worse results in comparison with $\mathrm{RM}$ than in CAIRSENSE project, where Cairclip sensors were used as well for a long-term monitoring in city of Decatur (Georgia, US; [4]). Weak correlation and significantly higher $\mathrm{NO}_{2}$ concentrations measured by Cairclip sensor than by reference monitors (SPR) in this study may indicate the possible effect of interference with some other oxides $\left(\mathrm{O}_{3}, \mathrm{SO}_{2}, \mathrm{CO}\right.$; [18], [19]). This effect of unfiltered interference may also be signalled by higher level of uncertainty of this sensor $(<30 \%$ reported by manufacturer $)$ which is slightly over the 
threshold defined by Data Quality Objectives given by the European Air Quality Directive $(2008 / 50 / \mathrm{EC} ;<25 \%$, see in review [10]).

The combined $\mathrm{O}_{3} / \mathrm{NO}_{2}$ Cairclip sensor performed in the best way from the whole set of sensors. Although the separation of these two oxides from the single value output is not clear (subtracting of values from $\mathrm{NO}_{2}$ Cairclip sensor leads to negative values), in comparison with summarization of $\mathrm{O}_{3}$ and $\mathrm{NO}_{2}$ values from $\mathrm{RM}$ we have gained a strong positive correlation and suitable SPR values.

Beside given sensors admitted lowered accuracy, there is additional risk of getting biased data, according to the non-standard meteorological conditions. Therefore, certain emphasis should be placed on data post-processing and their interpretation. Several ways how to validate the sensors data from the field measurement were already published. Most of them include the effect of air temperature, relative humidity, air pressure or wind speed to the multiple linear regressions [4], [18]. Based on the non-linearity of our data and on the known covariance of several meteorological parameters we calculated the dew point deficit as a variable including the combined information about the air temperature and humidity and we corrected the sensors measured values based on the nonlinear association between sensor's performance and this parameter. While in summer period the sensor's measurement quality (SPR) increased with decreased air humidity (i.e increased $T_{d}$ deficit, Fig. 3), in winter this relationship was surprisingly opposite (Fig. 5). Although we cannot explain this opposite relationship with dew point deficit in winter and in summer period, by this correction we achieved not only better coefficient of determination but also the validated concentrations corresponded much better to the RM values than the original ones in both seasons.

Although micro-sensors represent a great potential in expanding the possibilities of air quality monitoring (especially in hard-to-reach places, like vertical profiles and so on), the awareness about data quality of different types of sensors is very important. We believe that this correlational study could contribute to better understanding of performance of concrete types of electrochemical sensors.

\section{ACKNOWLEDGEMENTS}

We are grateful to Mark Rieder and Jan Macoun from the leadership of the CHMI for their interest in this topic and support in realisation of measurement, to Zdeněk Grepl, Vladimír Adamec and technicians from Envitech Bohemia, s.r.o., company for active participation and realisation of the field measurement, also to Luboš Hanka and Petr Sejkora from KELCOM International, spol. s r.o., company for cooperation and participation in testing the sensors for use in UAVs air quality monitoring. Finally, we are thankful to all co-authors and anonymous reviewers for their comments.

\section{REFERENCES}

[1] EPA, Smart City Air Challenge Resource Pages: Air Quality Sensors 2017. https://developer.epa.gov/air-quality-sensors/. Accessed on: 8 Mar. 2018.

[2] Castell, N. et al., Mobile technologies and services for environmental monitoring: The Citi-Sense-MOB approach. Urban Clim., 14, pp. 370-382, 2015. DOI: 10.1016/ j.uclim.2014.08.002.

[3] Snyder, E.G. et al., The changing paradigm of air pollution monitoring. Environ. Sci. Technol., 47, pp. 11369-11377, 2013. DOI: 10.1021/es4022602.

[4] Jiao, W. et al., Community air sensor network (CAIRSENSE) project: Evaluation of low-cost sensor performance in a suburban environment in the southeastern United States. Atmos Meas Tech, 9, pp. 5281-5292, 2016. DOI: 10.5194/amt-9-5281-2016.

[5] Williams, R. et al., Air Sensor Guidebook. US EPA, 2014. DOI: EPA/600/R-14/159. 
[6] Schneider, P., Castell, N., Vogt, M., Dauge, F.R., Lahoz, W.A. \& Bartonova, A., Mapping urban air quality in near real-time using observations from low-cost sensors and model information. Environ Int., 106, pp. 234-247, 2017. DOI: 10.1016/ j.envint.2017.05.005.

[7] Clements, A.L. et al., Low-cost air quality monitoring tools: from research to practice (a workshop summary). Sensors, 17, p. 2478., 2017. DOI: 10.3390/s17112478.

[8] Polidori, A., Air quality sensor performance evaluation center (AQ-SPEC). Pems Conf., pp. 1-33, 2015.

[9] Gerboles, M., Spinelle, L. \& Borowiak, A., Measuring air pollution with low-cost sensors, 2017.

[10] Castell, N. et al., Can commercial low-cost sensor platforms contribute to air quality monitoring and exposure estimates? Environ Int., 9, pp. 293-302, 2017. DOI: 10.1016/j.envint.2016.12.007.

[11] Pang, X., Shaw, M.D., Lewis, A.C., Carpenter, L.J. \& Batchellier, T., Electrochemical ozone sensors: A miniaturised alternative for ozone measurements in laboratory experiments and air-quality monitoring. Sensors Actuators, B Chem., 240, pp. 829837, 2017. DOI: 10.1016/j.snb.2016.09.020.

[12] Fishbain, B. et al., An evaluation tool kit of air quality micro-sensing units. Sci Total Environ., 575, pp. 639-648, 2017. DOI: 10.1016/j.scitotenv.2016.09.061.

[13] Borrego, C. et al., Assessment of air quality microsensors versus reference methods: The EuNetAir joint exercise. Atmos. Environ., 147, pp. 246-263, 2016. DOI: 10.1016/j.atmosenv.2016.09.050.

[14] Teledyne. Teledyne API, 2018. http://www.teledyne-api.com/. Accessed on: 5 Mar. 2018.

[15] Spinelle, L., Gerboles, M. \& Aleixandre, M., Report of laboratory and in-situ in itu validation of micro-sensor sensor for monitoring ambient air pollution. $\mathrm{O}_{12}$ : CairClip $\mathrm{O}_{3} / \mathrm{NO}_{2}$ of Cairpol (F). JRC Technical Reports, 2013. DOI: 10.2788/4277.

[16] Notario, A. et al., Behaviour and variability of local and regional oxidant levels (OX $=\mathrm{O}_{3}+\mathrm{NO}_{2}$ ) measured in a polluted area in central-southern of Iberian Peninsula. Environ. Sci. Pollut. Res., 20, pp. 188-200, 2013. DOI: 10.1007/s11356-012-0974-1.

[17] Zoest, Van V.M., Outlier Detection in Urban Air Quality Sensor Networks, 2018.

[18] Spinelle, L., Gerboles, M., Villani, M.G., Aleixandre, M. \& Bonavitacola, F., Field calibration of a cluster of low-cost available sensors for air quality monitoring. Part A: Ozone and nitrogen dioxide. Sensors Actuators B Chem, 215, pp. 249-257, 2015. DOI: 10.1016/j.snb.2015.03.031.

[19] Mead, M.I. et al., The use of electrochemical sensors for monitoring urban air quality in low-cost, high-density networks. Atmos. Environ., 70, pp. 186-203, 2013. DOI: 10.1016/j.atmosenv.2012.11.060.

[20] Masson, N., Piedrahita, R. \& Hannigan, M., Quantification method for electrolytic sensors in long-term monitoring of ambient air quality. Sensors (Switzerland), 15, pp. 27283-27302, 2015. DOI: 10.3390/s151027283.

[21] EPA, Air Sensor Toolbox 2017. https://www.epa.gov/air-sensor-toolbox/evaluationemerging-air-pollution-sensor-performance. Accessed on: 8 Mar. 2018. 